\title{
INERTIA IN COGNITIVE PROCESSES; THE ROLE OF ACCUMULATED INFORMATION IN ATTITUDE CHANGE
}

\author{
JOHN SALTIEL \\ Montana State University
}

\author{
JOSEPH WOELFEL \\ Michigan State University
}

\begin{abstract}
Research evidence is presented to support a new and simple theory of attitude formation and change. This theory posits that the attitude of any individual converges over time on the arithmetic mean of the attitude-pertinent information received by the individual. Consequently, the stability of an attitude is dependent on the number of messages out of which that attitude was formed. This formulation also implies that the emotional state or feelings of an individual and the degree of heterogeneity of influences to which he or she was exposed are unrelated to attitude change. Using a multi-stage, multi-time procedure, and instruments designed to detect and measure interpersonal influence, data provided by 135 high school students over a six-month interval support these hypotheses.
\end{abstract}

While the notion that cognitive processing of information may be too complex and unpredictable to be represented by a few simple quantitative laws or principles remains a suspicion even among some social scientists, the last decade of empirical research has produced many cases in which some of these processes have been described quite accurately with very simple quantitative formulations. Cliff (1972), for example, asked 31 subjects to estimate the favorability of 10 adjectives describing personality traits on a series of nine point scales. Subjects also rated the favorableness of all possible pairs of these adjectives on the same scales. Cliff found that the favorability of the pairs of adjectives could be predicted very accurately by the average favorability of the two component adjectives, for example,

$$
a_{12}=\frac{a_{1}+a_{2}}{2}
$$

where

$a_{1}=$ the favorableness of the first adjective, $a_{2}=$ the favorableness of the second adjective, $a_{12}=$ the favorableness of the pair taken together.

On the average, 96 percent of the variance in the favorability score of the pairs was accounted for by the simple average of their components. Monotonic transformations to account for potential curvilinearity were able to explain on the average only .025 additional percent of the variance.

In a more complex survey design, Woelfel and Haller (1971) measured the status aspirations (i.e., levels of education and occupational prestige to which subjects aspire) of a set of 99 high school students, and showed that about half of the variance in these expectations could be accounted for by the average status expectations of a set of independently identified "significant others" with whom the respondents reported communicating. In a study of the determinants of marijuana use, Woelfel and Hernandez (1972) found that 86 percent of the variance in rate of marijuana use by 341 U.S. and Canadian college students could be accounted for by a weighted average of the information about marijuana they reported having received. In this same vein, Reeves (1974) found that nearly half the variance in the extent to which young children see $\mathrm{TV}$ characters as real or fantasy can be accounted for by a weighted average of the opinions of a subset of their significant others. Woelfel, Woelfel, Gilham, and McPhail (1974) have similarly shown that 64 percent of the variance in attitudes toward French Canadian Separatism can be accounted for by a weighted average of messages received from media 
and interpersonal communications controlling for selected sociostructural variables, and Fink (1975) has demonstrated that a similar model accounts very well for the contagion of embarrassment. Mettlin (1973), using a design similar to that of Woelfel and Haller (1971) reported that the same general model accounts well for rate of cigarette smoking.

Many other such studies might be cited (e.g., Anderson, 1974; Woelfel \& Saltiel, 1974) but these suffice to indicate the promise of the hypothesis that the attitudes, beliefs, or other cognitive structures of individuals may well be relatively simple quantitative aggregates of information received by those individuals from diverse sources. Much of this research has been summarized recently by Woelfel and Saltiel (1974) and by Anderson (1974), who argues that the integration of individual cognitive elements into a generic whole generally takes one of five algebraic forms: adding, subtracting, averaging (weighted and unweighted), multiplying, and dividing. While Anderson finds it useful to consider these five algebraic combination rules separately, ${ }^{1}$ all of them can be seen readily to be special cases of the more general form of the first degree polynomial

$$
\mathrm{y}=\mathrm{u}_{1} \mathrm{x}_{1}+\mathrm{u}_{2} \mathrm{x}_{2}+\mathrm{u}_{3} \mathrm{x}_{1} \mathrm{x}_{2}
$$

where $y=$ the resultant cognitive aggregate

$\mathrm{x}_{1}, \mathrm{x}_{2}=$ two individual cognitive components (or messages received by an individual)

$\mathrm{u}_{1}=$ a weighting factor giving the net effect of the $i$ th term of the polynomial, i.e. , the partial slope

which, of course, is simply the familiar linear regression model with the interaction term $u_{3} x_{1} x_{2}$ specifically considered. Which of Anderson's five combination rules applies in any empirical situation is given by the pattern of coefficient values in (2), ${ }^{2}$ but unfortunately, Anderson provides no rigorous hypotheses about the conditions under which one pattern of coefficients should prevail over another. He calls the process whereby the coefficients are empirically fitted (by regression techniques) to the datafunctional measurement, and advocates it as an appropriate technique (Anderson, 1974).

It is quite possible (and follows implicitly from Anderson's notion of functional measurement) to interpret these coefficients themselves as substan- tive variables whose functional relations may be explained theoretically. Consider equation (3), for example, which depicts the simple situation where an individual whose attitude toward a topic is given by $a_{1}$ is in receipt of a message advocating a position toward that topic given by $a_{2}$. The new attitude, $a_{3}$, is assumed to be a weighted aggregate of the old attitude $\left(a_{1}\right)$ and the new message $\left(a_{2}\right)$

$$
\mathrm{a}_{3}=\mathrm{u}_{1} \mathrm{a}_{1}+\mathrm{u}_{2} \mathrm{a}_{2}
$$

In equation (3) the coefficient $u_{1}$ represents the net weight or effectiveness of the old attitude in establishing the new, and $\mathrm{u}_{2}$ represents the net weight or effectiveness of the new message. Each of these coefficients can be considered a substantive theoretical variable, where $u_{1}$ represents that quality (or those qualities) of the old attitude which resists change, and $\mathrm{u}_{2}$ that quality (or those qualities) of the message which produces change. The values of the coefficients as estimated empirically in the regression equation may be taken as the values of those variables in that context. ${ }^{3}$

While these regression-based estimates may be taken as accurate measures of the values of these underlying variables, still a theory which makes no a priori prediction of their relative values is of very limited predictive value. A theory which gave substantive interpretations to these coefficients and allowed a priori predictions of their values would be desirable.

\section{Theory:}

Let us assume for the moment a simple hypothetical attitude formation situation in which an individual who has no prior attitude toward the topic in question receives a set of $n$ independent messages, each one of which is assumed to be equally "effective" (i.e., each message is delivered by a source whose credibility is equal to each other source) and each of which represents some point along a unidimensional attribute representing the attitude domain. Since the individual is presumed to have no prior attitude toward the phenomenon in question, no term representing the old attitude is needed, and the model may be represented by equation (4).

$$
a_{1}=u_{1} m_{1}+u_{2} m_{2}+\ldots+u_{n} m_{n}
$$


Since we have further assumed all messages to be independent and equally effective, $u_{1}=u_{2}=\ldots=$ $u_{n}$, and each message may be assumed to account for $1 / n$th of the total effect, giving $u_{1}=u_{2}=\ldots=$ $\mathrm{u}_{\mathrm{n}}=1 / \mathrm{n}$, and thus

$$
a_{1}=\sum_{i=1}^{n} m_{1 \div n}
$$

Equation (5) shows clearly that, under these constraints, the resultant attitude will be the arithmetic mean of all positions proposed by the $n$ messages. Such a view is consistent with most balance or cognitive consistency models, (Heider, 1946; Festinger, 1957; Bruner, 1958) since the mean is an ideal balance point, given that it has the property

$$
\sum_{i=1}^{n}\left(x_{i}-\bar{x}\right)=0
$$

that is, deviations from the mean sum to zero.

If we designate the attitude formed under these circumstances as $a_{1}$ and assume the individual then receives $p$ additional messages $m_{n+1}, m_{n+2}$, $\ldots m_{n+p}$, again under the same constraints, these new messages would result in a second attitude which is also the average of those messages, i.e.,

$$
a_{2}=\sum_{i=n+1}^{m+p} m_{j p}
$$

Of central concern is the result of the aggregation of these two attitudes $a_{0}$ and $a_{1}$. Under the same constraints, this aggregate or resultant attitude $a_{3}$ is given by

$$
\begin{aligned}
a_{3} & =\sum_{i=1}^{n} m_{1}+\sum_{i=n+1}^{n+p} m_{i} / n+p \\
& =n a_{1}+p_{2} / n+p \\
& =n / n+p a_{1}+p / n+p a_{2}
\end{aligned}
$$

In its final form, equation (8) is instructive because it shows that the relative contribution of each of the two sets of message $a_{1}$ and $a_{2}$ is given by the relative sizes of the coefficients $n / n+p$ and $p / n+p$. Each of these coefficients, in turn, represents the ratio of the number of messages in each set to the overall total number of such messages.

If we arbitrarily consider $a_{1}$ to represent the attitude resulting from the set of messages $m_{1}, m_{2}$, $\ldots m_{n}$ received prior to some time $t_{1}$, and $a_{2}$ the average value of those messages received after that time, then equation (8) implies that the resistance to change of the old attitude will be a function of $n$, the number of messages out of which it was formed, and the effectiveness of the new set of messages $a_{2}$ will be a function of the number of such messages, $p$.

Substituting this work into equation (3) yields

$$
\mathrm{u}_{\mathrm{i}}=\mathrm{n} / \mathrm{n}+\mathrm{p}, \mathrm{u}_{2}=\mathrm{p} / \mathrm{n}+\mathrm{p} \text {. }
$$

These results can easily be generalized to $s$ sources as

$$
u_{i}=n_{i} / s,
$$

where $u_{j}=$ the coefficient of the $i$ th information source, $\mathrm{n}_{\mathrm{i}}=$ the number of messages in the $i$ th source, $\mathrm{s}=$ the number of messages from all sources.

The results of this work, therefore, yield a theory which gives substantive interpretations to the coefficients in the general linear equation and makes quantitative predictions about their values. Without too much oversimplification, the theory can be stated verbally as follows: Each "unit" of information (called here a "message") is assumed to be associated with a measurable "inertia" or resistance to change. Thus, the resistance to change of any attitude is linearly proportional to the number of such units of information accumulated into it. This quality of resistance to change is called inertial mass. It should be noted as well that it is not necessary to assume the value of the inertial mass of each unit of information to be the same, although we have done it here for simplicity of exposition. Techniques for the measurement of the inertial mass of different units of information are given in Woelfel and Hernandez (1972).

While simple, quantitative and apparently reasonable, these hypotheses are at variance with those theories that rest in a psychologically gratifying state as a cause for behavior (see Roloff, 1974). The theory presented here implies that such variables as the degree of satisfaction or dissatisfaction with which an individual views an attitude he or she holds are unrelated to the likelihood that the attitude will change. As a hypothesis, then, it may be stated: the amount of attitude change over a time interval $t_{1}$ $-t_{0}$ is not dependent on any emotional state or feeling of the individual prior to or during the interval.

Furthermore, since the equations make no refer- 
ence to the variance around the mean, the homogeneity or heterogeneity of the influences to which an individual has been exposed has no consequences for the stability of an attitude. This prediction diverges from those theories that assume that homogeneous influences tend to produce rigid, dogmatic attitudes which resist change (Adorno, 1950; Rokeach, 1960), while heterogeneous patterns of influence conduce toward flexibility and change. Again, this may be expressed as a hypothesis: the amount of attitude change over a time period $t_{1}-t_{0}$ is not dependent on the heterogeneity of the influences forming the attitude prior to $t_{0}$.

This study presents research findings bearing directly upon these hypotheses.

\section{METHOD}

\section{The Variables}

1. The dependent variable-attitude change over time $\left(X_{1}\right)$

Since the theory assumes that rate of attitude change for a given force is inversely proportional to the number of messages out of which the original attitude was formed, the dependent variable in this study is the absolute amount of attitude change over time. The attitude used for study is degree of integration with American societal values. The concept of value integration refers to the varying degrees of valuation an individual places on those objects that are presumably meaningful to all segments of the population, whether they accept or reject them (Falding, 1965). In this research, the degree of value integration was measured by a 17 -item, Likert-type scale that was designed to measure attitudes toward a selected list of values generally considered to be at the core of American ideology (Saltiel, 1972). The items were drawn from several works which have discussed the dominant themes and systems of belief that constitute what can be considered the overall pattern of value orientations in America (Parsons, 1951; Kluckholn, 1958; Williams, 1960). These themes include achievement and success, efficiency and practicality, progress, formal equality, freedom from control, external conformity, and science and secular rationality. An Alpha coefficient of .74 was obtained, which is typical for measures of concepts of this type.

This scale was administered twice to the same sample of high school students over an interval of six months. The absolute value of the difference of the scale scores was taken as the measure of attitude change.

\section{Number of messages $\left(X_{6}\right)$}

The measurement of the number of messages that went into the original attitude implies a procedure whereby the exact significant others for the sample of individuals could be detected and the amount of information they transmitted could be determined. Identification was done with a variant of the Wisconsin Significant Other Battery (Haller \& Woelfel, 1969,1971 ) which identifies the specific influential others for an individual's attitude by using each item on the attitude scale to cue the respondent to think of those persons from whom he or she has received information about the object in question. The questions were of the form: "Who have you talked to about ... ?"' Note that the questions do not ask individuals whom they like, who influenced them, or whether or not the source was credible. After naming each other person, the focal individuals were asked to report how often they communicated with those others about each object in question. An index was then constructed by multiplying the number of significant others for each individual by the average amount of communication the individual reported having with all significant others. The resulting index is the product of the number of persons with whom a respondent has interacted about the topic area and the average amount of communication he or she reports having had with each person. This should consequently provide a measure highly correlated with the absolute amount of information the individual has received about the dependent attitude cluster prior to the onset of the research.

3. Degree of heterogeneity in significant other expectations $\left(\mathrm{X}_{2}\right)$ 
This variable refers to the degree of homogeneity or heterogeneity of the patterns of influence to which each individual has been exposed. Measurement of this variable involves a multi-stage procedure whereby the sources of information for the respondent are identified, the expectations of these others are measured, and the variability of these expectations is determined. Having identified each individual's significant others by the procedure outlined above, these others were then asked to respond to a mailed questionnaire containing attitudinal items identical to those used for the focal individuals. Since each focal individual had a variable number of significant others, interpersonal influence was measured, following the theory, by taking the mean of those expectations. The heterogeneity of expectations was then calculated as the variance around that mean. ${ }^{4}$

\section{Emotional state and feelings $\left(X_{3}-X_{5}\right)$}

This set of variables very generally is intended to refer to the degree of satisfaction or dissatisfaction the individual feels either toward the attitude specifically or himself or herself in general. Operationalizations in this research are two-fold: subjective attitude stability and a subjective measure of stress.

a. Subjective attitude stability $\left(\mathrm{X}_{5}\right)$

This variable was measured by two Likert-type items that asked how strongly the respondent felt about her or his opinion, and how certain she or he was about that answer. These two questions were asked after each of the 17 attitudinal items and the sum of all 34 measures was taken as the index of subjective stability.

As a corollary of this measure, the same variables were measured by the same 34 questions for each of an individual's significant others. These 34 questions were summed within each significant other, and these sums averaged across all significant others for each person. The resulting variable is called the average subjective stability of the significant others' expectations. $\left(\mathrm{X}_{3}\right)$

b. Index of psychological stress $\left(\mathrm{X}_{4}\right)$

Although the theoretical formulation we have proposed makes no reference to psychological dis- order, several current theories of attitude change have as their root concepts some psychologically gratifying state as a motivation for behavior. In order to test the hypothesis that psychological stress is unrelated to attitude change, an instrument which purports to measure incipient mental illness was administered to the focal individuals at the time their original attitudes were measured. This instrument, developed by Langner (1962), and modified slightly by Mettlin and Woelfel (1975) to improve its reliability, contains 22 items which are primarily psycho-physiological in nature, but also deal with feelings of depression and withdrawal. Although this scale is of questionable validity as an indicator of psychological illness, it does seem to be related to stress (Hough, 1969) which is satisfactory for the purposes of this research.

\section{Structural factors $\left(X_{7}-X_{12}\right)$}

Different locations in social structure differentially expose the individual to various kinds of significant others, and to various kinds and amounts of information that those others communicate. Such variables, in addition to their substantive interest, serve as the fixed constants or exogenous variables necessary to identify the path-analytic model which represents the theory. In this research, sex, age, and the SES of an individual's family are considered as measures of distinct locations in social structure that are relevant for the kinds and amounts of information the individual receives. SES was measured as the prestige level of the father's occupation as rated by the Duncan revision of the NORC scale (Duncan, 1961), level of father's educational attainment, and the subjective relative wealth of the family as perceived by the respondent.

\section{Research Design}

The research procedure involved a multi-stage, multi-time design. Data were collected from 186 high school juniors and seniors from a large city in Illinois. The particular high school chosen allowed for a wide range in SES. The original sample responded to items measuring the attitudes of the focal individuals towards societal values and items 
FIGURE 1.

Path Diagram Representing Alternative Causal Hypotheses in Attitude Change

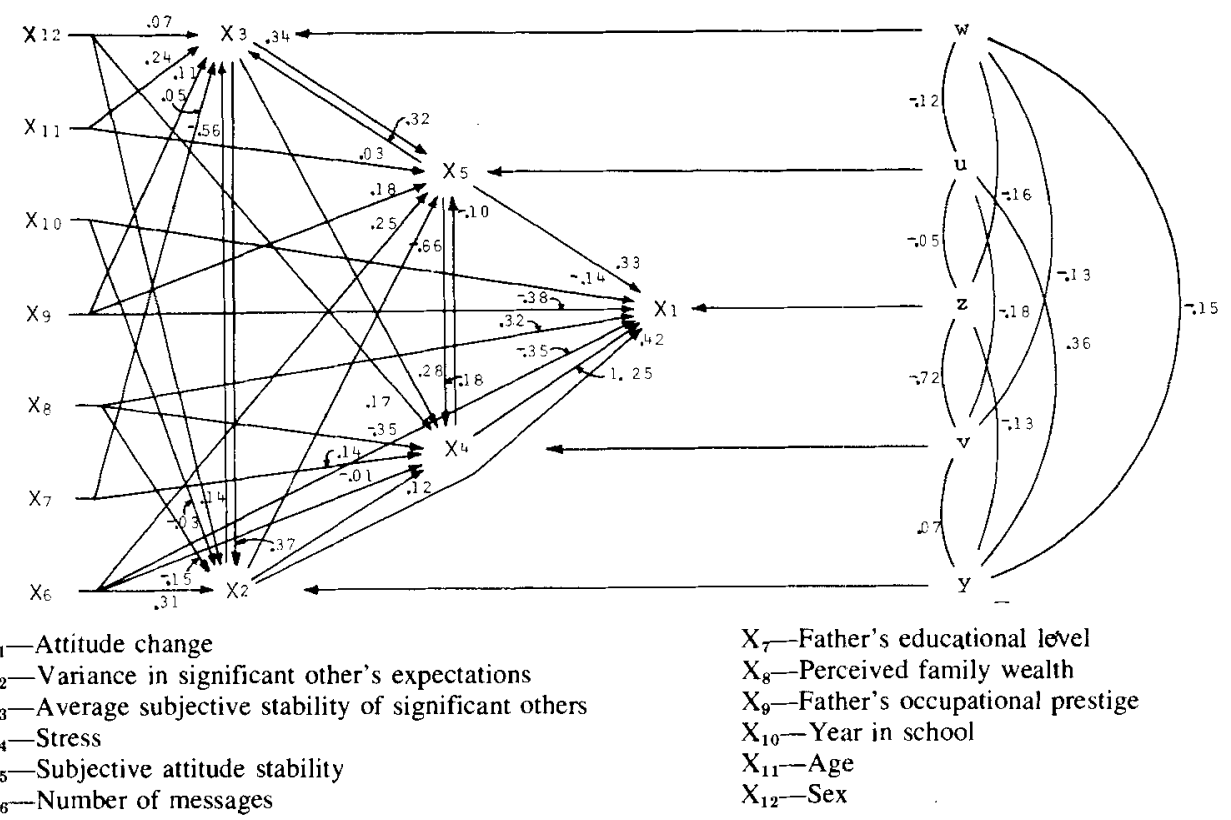

detecting the exact significant others for each individual. Each significant other was then contacted by mail and their attitudes toward the same items were measured. The final stage involved administering the attitude questionnaire to the original student sample after an interval of six months. This second administration yielded 135 usable cases. The instruments identified 1238 significant others of whom 58 percent responded to the mailed questionnaire. This provided usable data from 714 significant others.

Quite clearly, the theory assumes that the amount of attitude change over time is a function not only of the old attitude's resistance to change $\left(\mathrm{X}_{6}\right)$, but of the value and amount of the new information as well. While such precise measures are extremely desirable, measurement of the receipt of information across the attitude change interval was beyond the scope of this research. Consequently, the stated hypotheses were tested on the assumption that the forces for attitude change were randomly distributed across the sample. This assumption is proba- bly only partly true, of course, and will result in reductions of explained variance in the research reported here.

The absence of this variable, furthermore, precludes testing equation 8 in the form derived. This is not a serious drawback, however, as the following calculations show:

First, subtracting $a_{1}$ from both sides of ( 8 ) yields

$$
a_{3}-a_{2}=n / n+p a_{1}+p / n+p a_{2}-a_{1}
$$

This manipulation shows clearly that $a_{3}-a_{1}$ (the amount of attitude change occurring) will converge on zero as $n$ becomes large relative to $p$. Thus we can see that $n$, the number of messages or inertial mass of the initial attitude, is inversely related to the absolute value $\left|a_{3}-a_{1}\right|$ of the change in attitude over time.

This reasoning yields the hypothetical model shown in Figure 1. Structural factors $\left(X_{9}-X_{12}\right)$ and number of messages $\left(\mathrm{X}_{6}\right)$ are considered as predetermined variables. The primary dependent variable is the absolute amount of attitude change 


\begin{tabular}{|c|c|c|c|c|c|c|c|c|c|c|c|c|}
\hline Observed C & $\begin{array}{l}\text { orrel } \\
\text { for }\end{array}$ & $\begin{array}{l}\text { atior } \\
135\end{array}$ & $\begin{array}{r}\text { T } \\
\text { ns of } \\
\text { Higl }\end{array}$ & $\begin{array}{l}\text { ABL } \\
12 \\
\text { Scl }\end{array}$ & $\begin{array}{l}\text { E1 } \\
\text { Attit } \\
\text { hool }\end{array}$ & $\begin{array}{l}\text { ude } \\
\text { Stud }\end{array}$ & $\begin{array}{l}\text { Cha } \\
\text { lents }\end{array}$ & nge & Vari & ables & & \\
\hline & $X_{12}$ & $x_{11}$ & $x_{10}$ & $\mathrm{X}_{\theta}$ & $\mathrm{X}_{\mathrm{f}}$ & $x_{1}$ & $\mathrm{X}_{8}$ & $\mathrm{X}_{\mathrm{s}}$ & $x_{4}$ & $\mathrm{X}_{3}$ & $\mathrm{x}_{2}$ & $x_{1}$ \\
\hline $\operatorname{Sex}\left(X_{12}\right)$ & 1.00 & & & & & & & & & & & \\
\hline Age $\left(X_{11}\right)$ & .10 & 1.00 & & & & & & & & & & \\
\hline Year in School (YR) $\left(\mathrm{X}_{19}\right)$ & .26 & .65 & 1.00 & & & & & & & & & \\
\hline Father's Occupation $\left(X_{9}\right)$ & .07 & .08 & .07 & 1.00 & & & & & & & & \\
\hline Relative Wealth $\left(\mathrm{X}_{\varepsilon}\right)$ & .06 & .11 & .06 & .40 & 1.00 & & & & & & & \\
\hline Father's Education $\left(X_{7}\right)$ & .06 & .02 & -.04 & .71 & .52 & 1.00 & & & & & & \\
\hline Number of Messages $\left(\mathrm{N}_{0}\right)\left(\mathrm{X}_{\hat{b}}\right)$ & .34 & .11 & .24 & .08 & .04 & .06 & 1.00 & & & & & \\
\hline $\begin{array}{l}\text { Respondent's Attitude } \\
\text { Stability (SAS) }\left(X_{3}\right)\end{array}$ & -.19 & -.01 & -.02 & .05 & .11 & .07 & .05 & 1.00 & & & & \\
\hline $\begin{array}{l}\text { Psychological Stress } \\
\text { (STRESS) }\left(X_{4}\right)\end{array}$ & .13 & .04 & .05 & .02 & $-.2 \mathrm{t}$ & .02 & .07 & -.15 & I. 00 & & & \\
\hline $\begin{array}{l}\text { S.O.'s Attitude } \\
\text { Stability (MSAS) }\left(X_{3}\right)\end{array}$ & -.06 & .15 & .06 & .04 & .15 & .06 & -.08 & .16 & 06 & 1.00 & & \\
\hline $\begin{array}{l}\text { Variance in } S . O \\
\text { Attitude (OSOl) }\left(X_{2}\right)\end{array}$ & .17 & .18 & .12 & .26 & -.01 & .17 & .27 & -.17 & .08 & .10 & 1.00 & \\
\hline $\begin{array}{l}\text { Change in Attitude }\left(X_{1}\right) \\
\text { ( } \triangle \text { DVI) }\end{array}$ & .01 & .01 & -.13 & -.14 & -.08 & -.01 & -.19 & .27 & .05 & .17 & -.02 & 1.00 \\
\hline
\end{tabular}

[ $\left.\Delta \mathrm{DVI}\left(\mathrm{X}_{1}\right)\right]$. The other endogenous variables, change. Additionally, since we wish to test the hypothesis that heterogeneity of expectations, subjective stability, and stress are unrelated to attitude heterogeneity of expectations [OSOI $\left(\mathrm{X}_{2}\right)$ ], subjective attitude stability of the respondent [SAS $\left(\mathrm{X}_{3}\right)$ ], mean subjective attitude stability of significant others [MSAS $\left(\mathrm{X}_{5}\right)$ ], and psychological stress [STRESS $\left(\mathrm{X}_{4}\right)$ ], are treated as temporally prior to attitude change, and are measured at $t_{1}$. Since the theory predicts that the resistance to change of an attitude is wholly dependent on the number of messages that went into its formation, we have drawn a direct path from number of messages to attitude change when controlling for inertial mass, we have included direct paths between these variables and attitude change in the model. Finally, although a more thorough analysis goes beyond the scope of this paper, we have completed the model by constructing plausible paths from the appropriate exogenous variables to the four "secondary" endogenous variables, and the paths between these endogenous variables themselves. A more thorough discussion of the model along with the structural equations that describe it is presented below.

\section{RESULTS}

The zero order correlations among the variables are presented in Table 1. Consistent with the theory, the correlation between attitude change and inertial mass of the attitude is negative and significant $\left(r_{6.1}\right.$ $=-.19$ ) and the correlation between attitude change and heterogeneity of influence is zero $\left(\mathrm{r}_{2.1}=-.02\right)$. Equally interesting, and also predicted by the theory, the correlation between stress and attitude change is also zero $\left(r_{4.1}=.05\right)$. There are, however, substantial positive correlations between the individual's strength of attitude and subsequent attitude change $\left(r_{5.1}=.27\right)$ and the average strength of significant others' attitudes and subsequent change in the individual's attitude $\left(r_{3.1}=.17\right)$, a result predicted neither by conventional theory nor by the new. The coefficients $\left(r_{10.1}=-.13\right)$ and $\left(r_{9.1}\right.$ $=-.14$ ) indicate that older children and higher status children exhibit somewhat less attitude change over time than do their younger and lower status peers.

Interesting as these results may be, they do not take into account the many spurious relationships possible in the data which may have given rise to a 
TABLE 2

Standardized Path Coefficients for Equations Represented in Figure 1

\begin{tabular}{|c|c|c|c|c|c|c|c|c|c|c|}
\hline \multirow[t]{2}{*}{$\begin{array}{l}\text { Independent } \\
\text { Variables }\end{array}$} & \multicolumn{2}{|c|}{$\begin{array}{l}\text { SAS } \\
\left(\mathbf{X}_{5}\right)\end{array}$} & \multicolumn{2}{|c|}{$\begin{array}{c}\text { PSYCHSTR } \\
\left(\mathrm{X}_{4}\right)\end{array}$} & \multicolumn{2}{|c|}{$\underset{\left(\mathbf{X}_{3}\right)}{\text { MSAS }}$} & \multicolumn{2}{|c|}{$\underset{\left(\mathbf{X}_{2}\right)}{\text { OSOI }}$} & \multicolumn{2}{|c|}{$\begin{array}{c}\Delta \mathbf{D V I} \\
\left(\mathbf{X}_{1}\right)\end{array}$} \\
\hline & $\mathbf{p}$ & $\mathbf{t}$ & $\mathbf{p}$ & $\mathbf{t}$ & $\mathbf{p}$ & $\mathbf{t}$ & $\mathbf{p}$ & $\mathbf{t}$ & $\mathbf{p}$ & $\mathbf{t}$ \\
\hline $\operatorname{Sex}\left(\mathrm{X}_{12}\right)$ & - & - & .17 & .11 & .07 & .36 & .14 & 1.09 & - & - \\
\hline Age $\left(X_{11}\right)$ & .03 & .09 & - & - & $.24 *$ & 1.94 & - & - & - & - \\
\hline YR $\left(X_{10}\right)$ & - & - & - & - & - & - & -.03 & -.26 & -.14 & -.99 \\
\hline FATHOCCL $\left(\mathrm{X}_{9}\right)$ & .18 & .60 & - & - & .11 & .58 & - & - & $-.38^{*}$ & -1.35 \\
\hline WEALTH $\left(\mathrm{X}_{\varepsilon}\right)$ & - & - & -.35 & -.50 & - & - & -.15 & -.92 & .32 & 1.14 \\
\hline FATHED $\left(X_{7}\right)$ & - & - & .14 & .55 & .05 & .32 & - & - & - & - \\
\hline No. of Messages $\left(\mathrm{X}_{6}\right)$ & .25 & .83 & -.01 & -.01 & - & - & $.31 *$ & 2.27 & $-.35^{*}$ & -1.34 \\
\hline SAS $\left(X_{5}\right)$ & - & - & .18 & .03 & .32 & .47 & - & - & .33 & .41 \\
\hline PSYCHSTR $\left(\mathrm{X}_{4}\right)$ & -.10 & -.10 & - & - & - & - & - & - & 1.25 & .91 \\
\hline $\operatorname{MSAS}\left(\mathrm{X}_{3}\right)$ & .34 & .25 & .28 & .39 & - & - & .87 & 1.04 & - & - \\
\hline $\mathrm{OSOI}\left(\mathrm{X}_{2}\right)$ & -.66 & -.51 & .12 & .21 & $-.56^{*}$ & -1.29 & - & - & .42 & .41 \\
\hline$\Delta D V I\left(X_{1}\right)$ & - & - & - & - & - & - & - & - & - & - \\
\hline
\end{tabular}

zero-order pattern like this one. Much more meaningful, therefore, are the results of the two stage least squares path analysis presented in Figure 1 and Table 2. paths from the endogenous variables to attitude change. Again, as predicted by the theory, none of these paths have values significantly different from zero. Although these coefficients appear sizable, they have large standard errors and overestimate the

$$
\begin{aligned}
& X_{1}=p_{12} X_{2}+p_{14} X_{4}+p_{15} X_{5}+p_{16} X_{6}+p_{18} X_{8}+p_{19} X_{9}+p_{1.10} X_{10}+p_{12} Z \\
& X_{2}=p_{23} X_{3}+p_{26} X_{6}+p_{28} X_{8}+p_{2.10} X_{10}+p_{2.12} X_{12}=p_{2 y} Y \\
& X_{3}=p_{32} X_{2}+p_{35} X_{5}+p_{37} X_{7}+p_{39} X_{9}+p_{3.11} X_{11}+p_{3.12} X_{12}+p_{3 \mathrm{w}} W \\
& X_{4}=p_{42} X_{2}+p_{43} X_{3}+p_{45} X_{5}+p_{46} X_{6}+p_{47} X_{7}+p_{48} X_{8}+p_{4.12} X_{12}+p_{4 v} V \\
& X_{5}=p_{52} X_{2}+p_{53} X_{3}+p_{54} X_{4}+p_{56} X_{6}+p_{59} X_{9}+p_{5.11} X_{11}+p_{5 u} U
\end{aligned}
$$

$\mathrm{X}_{1}=$ Amount of attitude change

$\mathrm{X}_{2}=$ Heterogeneity of expectations

$\mathrm{X}_{3}=$ Significant others' subjective attitude stability

$\mathrm{X}_{4}=$ Psychological stress

$\mathrm{X}_{5}=$ Ego's subjective attitude stability

$\mathrm{X}_{6}=$ Number of messages

Although caution should be exercised in interpreting these coefficients, the pattern of findings is extremely interesting. The most important finding is the path from $X_{6}$ (Number of messages) to the dependent attitude change variable. The value of this coefficient is especially impressive when it is recalled that we have not measured the new information that was transmitted over the time interval. Lack of these data is reflected in the large path value from the residual.

A second important set of findings concerns the size of the relationships. This is especially true in
$X_{7}=$ Father's level of educational attainment

$\mathrm{X}_{\varepsilon}=$ Subjective relative wealth of family

$\mathrm{X}_{9}=$ Father's occupational prestige level

$\mathrm{X}_{10}=$ Year in school

$X_{11}=$ Age

$X_{12}=\operatorname{Sex}$

the case of the path from STRESS to $\triangle D V I$ where the bias is reflected in the high negative correlation $\left(r_{\mathrm{zv}}=-.72\right)$ between the residuals. Because of this, this path was removed from the analysis and a new set of coefficients was computed. In this procedure, since our primary concern is with the attitude change variable, the structural equations for the other endogenous variables were not altered. The new equation for $\triangle D V I$ is:

$$
\begin{aligned}
& \text { II } X_{1}=p_{1.10} X_{10}+p_{1.9} X_{9}+p_{1.8} X_{8} \\
& +p_{1.6} X_{6}+p_{15} X_{5}+p_{12} X_{2}+p_{12} Z
\end{aligned}
$$


TABLE 3

Standardized Path Coefficients to Attitude Change $\left(X_{1}\right)$ for Four Structural Models

\section{Independent \\ Variables}

$\operatorname{Sex}\left(X_{12}\right)$

Age $\left(X_{11}\right)$

YR $\left(X_{10}\right)$

FATHOCCL $\left(\mathrm{X}_{9}\right)$

WEALTH $\left(\mathrm{X}_{8}\right)$

FATHED $\left(\mathrm{X}_{7}\right)$

$\mathrm{N}_{0}\left(\mathrm{X}_{6}\right)$

SAS $\left(X_{5}\right)$

STRESS $\left(X_{4}\right)$

$\operatorname{MSAS}\left(\mathrm{X}_{3}\right)$

OSOI $\left(\mathrm{X}_{2}\right)$
I

$\mathbf{p}$
-
$-\overline{.14}$
-.38
.32
$-\overline{.35}$
.33
1.25
$\overline{.42}$

II

$\mathbf{t}$

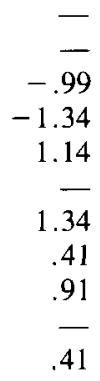

p

$-\overline{-}$
-.13
-.39
.12
$-\overline{.38}$
-.11
-
.95
III

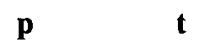

$$
\begin{array}{r}
- \\
-1.08 \\
-1.56 \\
.77 \\
-1.63 \\
-.19 \\
-\overline{-} \\
1.26
\end{array}
$$

IV

p t t

$$
\overline{-} \overline{.93}
$$$$
\begin{array}{r}
-.93 \\
-1.03
\end{array}
$$$$
\overline{-}-\overline{08}
$$$$
-.12
$$$$
-.02
$$$$
.26
$$$$
-1 . \overline{18}
$$$$
-1.18
$$$$
-.97
$$

The resulting estimates of the path coefficients were:

$\mathrm{p}_{1.10}=-.13(\mathrm{t}=-1.08), \mathrm{p}_{1.9}=-.39(\mathrm{t}=-1.56)$,

$\mathrm{p}_{1.8}=.12(\mathrm{t}=.77), \mathrm{p}_{16}=-.38(\mathrm{t}=-1.63)$,

$\mathrm{p}_{1.5}=-.11(\mathrm{t}=-.19), \mathrm{p}_{1.2}=.95(\mathrm{t}=1.26)$

Elimination of this path also changes the values of the residual correlations as follows:

$r_{u z}=.02, r_{v z}=-.01, r_{w z}=-.35, r_{y z}=-.53$.

Examination of these data (particularly the residual correlation $r_{y z}=-.53$ ) suggested that the path value from OSOI to $\triangle D V I$ was also inflated; consequently, it was removed and another set of coefficients computed based on the following equation: III $\mathrm{X}_{1}=\mathrm{p}_{1.10} \mathrm{X}_{10}+\mathrm{p}_{1.9} \mathrm{X}_{9}+\mathrm{p}_{1.8} \mathrm{X}_{\varepsilon}+\mathrm{p}_{1.6} \mathrm{X}_{6}+\mathrm{p}_{12} Z$.

At this point only one path from an endogenous variable to attitude change remained $\left(\mathrm{p}_{15}\right)$. Again, examination of this path value and the residual correlations, as summarized in Tables 3 and 4, suggested that this path be eliminated as well, particularly since the residual correlation $r_{u z}=+.51$ indicates that the path $\mathrm{p}_{12.8}=-.44$ is too strongly negative. The new coefficients were estimated by the following equation:

IV $X_{1}=p_{1.10} X_{10}+p_{1.9} X_{9}+p_{1.8} X_{8}+p_{1.6} X_{6}+p_{1 z} Z$. The resulting model contains only paths from the exogenous variables to attitude change. Examination of the coefficients shows that only the path from $\mathrm{X}_{6}$, Number of Messages $\left(\mathrm{N}_{0}\right)$, to attitude change is significant. Additionally, all of the residual correlations are now in the acceptable range.

A careful examination of the results of these procedures reveals that the most satisfactory rep- resentation of the overall pattern of these data is accomplished by a model in which attitude change is independent of the interrelationships among stress, heterogeneity of expectations, individual subjective attitude strength, and average subjective strength of significant others' attitudes. This result is represented in Figure 2, where only those coefficients directly relevant to the attitude change process have been filled in. (The remainder are as in Figure 1.) Furthermore, this result is exactly the pattern predicted by the theory, and clearly contradicts the key hypotheses drawn from more conventional socio-psychological theory. The only significant effect on attitude change consistent with the pattern of these data is the inverse relationship between the inertial mass of the attitude and its subsequent change, a result clearly and uniquely predicted by the theory.

\section{DISCUSSION}

Although causal inferences and generalizations to other samples must proceed with extreme caution in the case of preliminary studies of complex causal phenomena like this one, within this sample: (1) attitude change over time was inversely related to the amount of information the individual had accumulated about the attitude in question; (2) attitude change over time was not dependent on the specific affective feelings the individual had toward the attitude or on the generalized emotional state (stress) of the individual; and (3) attitude change over time was independent of the homogeneity or heterogeneity of information about the attitude 
FIGURE 2.

Model IV:

Schematic Representation of a Model of Attitude Stability

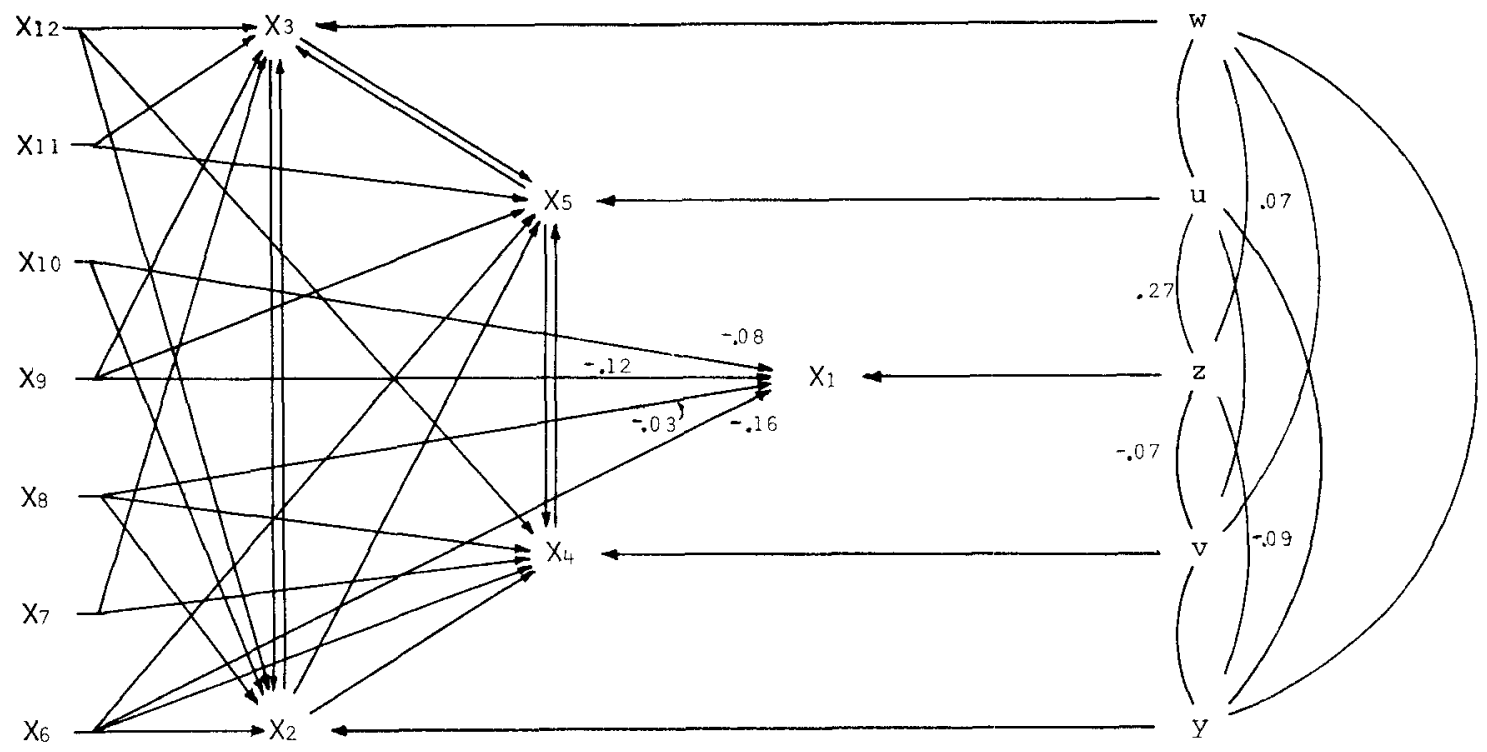

which the individual had received. Data were provided by 135 high school students and 1238 of their significant others over a six-month interval.

Should this pattern of results be borne out in subsequent research in other contexts, the implications for communication theory would be substantial. Most obviously, this research indicates that the quantity of information received by an individual is at least as important for attitude stability and change as its quality or source. Secondly, these data suggest that the affective psychological states typically associated with attitude stability and change in theoretical work may be of substantially less importance than has been suspected previously.

Most important, however, are the dynamic implications of the new theory. Both the theory and the research reported here suggest a dynamic view in which more or less "massive" attitudes are constantly impacted with information. The rate at which the attitude will converge on the average value of messages received (others factors equal) is an inverse function of the "massiveness" of the attitude, which in turn is a function of the amount of information out of which the attitude was originally constituted, and a direct function of the amount of information present in the incoming messages. Such a view would account readily for such phenomena as the greater attitude flexibility of the young as opposed to the old; for the greater ease with which the "image" of less well-known politicians may be changed than that of public figures of long standing; and in general, for the relative difficulty of changing attitudes central to the individual's life compared to those more peripheral. At any rate, these findings clearly suggest that the true dependent variable for attitudinal studies should be the rate of change over time, since attitudes are presumed to converge on the (changing) mean expectation of others over time, and the rate of convergence is given by the magnitude of the force and the "massiveness" of the attitude.

\section{NOTES}

1. Anderson separates these five cases since they refer to distinct empirical situations. Thus the adding 
TABLE 4

Correlations Between Residuals of Endogenous Variables and Attitude Change for Four Structural Equations

\section{Residuals \\ SAS $\left(X_{u}\right)$ \\ STRESS $\left(X_{v}\right)$ \\ $\operatorname{MSAS}\left(\mathrm{X}_{\mathrm{w}}\right)$ \\ OSOI $\left(\mathrm{X}_{\mathbf{y}}\right)$}

I

$-.05$

$-.72$

$-.16$

$-.13$
Structural Equations for $\mathbf{X}_{1}$

II III

$\begin{array}{rr}.02 & .51\end{array}$

$\begin{array}{ll}-.02 & -.51 \\ -.35 & -.17\end{array}$

$-.35-.02$

$-.53-.16$
IV

.27

$-.07$

.07

$-.09$ model might refer to the process of determining the value of a basket of commodities when several additional commodities are added to it. Similarly, a subtracting model might apply to the case in which commodities are subtracted from the basket (See Anderson, 1974).

2. Thus, where $u_{1}=1, u_{2}=1$ and $u_{3}=0$, the model is an adding model. Where either $u_{1}$ or $u_{2}=-1$ and $u_{3}=0$, the model is subtractive. Where $u_{1}=u_{2}=0$ and $u_{3}=1$, it is a multiplying model; where $\mathrm{u}_{1}=\mathrm{u}_{2}=0$ and $\mathrm{u}_{3}=$ either $1 / x_{1} 2$ or $1 / x_{2} 2$, the model is a dividing model. Where $\mathrm{u}_{1}=1 / 2, \mathrm{u}_{2}=1 / 2$ and $\mathrm{u}_{3}=0$, it is an averaging model. Of course there is no theoretical reason why these coefficients could not take on any real values, and they are not restricted to the simple patterns listed here. The point is simply to make clear that all of Anderson's models are special cases of the general model given in (2).

3. These variables may be considered derived variables following Torgerson (1958). The attribution of causality to the message and/or the attitude in question presupposes that competing alternative causal factors have been controlled.

4. The variance, i.e., $\sum_{\mathrm{i}=1}\left(\mathrm{X}_{\mathrm{i}}-\overline{\mathrm{X}}\right) 2 / \mathrm{n}$, can be seen as the average squared discrepancy between message sources and the average of all messages. It might well seem that the total discepancy, i.e., $\sum_{i=1}\left|\left(X_{i}-\bar{X}\right)\right|$, or possibly $\sum_{\mathrm{i}=1}\left(\mathrm{X}_{\mathrm{i}}-\overline{\mathrm{X}}\right) 2$ would be more clearly related to psychological stress, and Mettlin \& Woelfel (1974) report such a finding. In the present case, corelations of these variables and stress differ by less than .02 .

\section{REFERENCES}

ADORNO, T.W., FRENKEL-BRUNSWIK, E., LEVINSON, D.J., \& SANFORD, R.W. The authoritarian personality. New York: Harper, 1950.

ANDERSON, N.H. Cognitive algebra: Integration theory applied to social attribution. In L. Ber- kowitz (Ed.), Advances in experimental social psychology, Vol. 7. New York: Academic Press, 1974, 2-101.

BRUNER, J.S. Social psychology and perception. In E.E. Maccoby, T.M. Newcomb, \& E. Hartley (Eds.), Readings in social psychology. New York: Holt, Rinehart and Winston, 1958, 85-94.

CLIFF, $N$. Consistencies among judgments of adjective combinations. In R.N. Shephard, S.B. Neriove and A.K. Romney (Eds.), Multidimensional scaling: Theory and applications in the behavioral sciences. New York: Seminar Press, 1972, 163-182.

DUNCAN, O.D. A socioeconomic index for all occupations. In A.J. Reiss, Jr. (Ed.), Occupations and social status. New York: The Free Press, 1961, 263-275.

FALLDING, H. The empirical study of values. American Sociological Review, 1960, 30, 223-233.

FESTINGER, L.A theory of cognitive dissonance. Evanston: Row, Peterson and Company, 1957.

FINK, E.L. An empirical analysis of vicarious embarrassment: A study of social interaction and emotion. Unpublished doctoral dissertation, Department of Sociology, University of Wisconsin, 1975.

HALLER, A.O.,\& WOELFEL, J. The Wisconsin significant other battery. United States Office of Education, Project Number 5-1170, Final Report, 1969.

HEIDER, F. Attitudes and cognitive organization. Journal of Psychology, 1946, 21, 107-112.

HOUGH, R.L. Structural stress, anomia, and equivocal deviance. Urbana: University of Illinois, Rural Industrial Development Project, Working Paper No. 2., 1969.

KLUCKHOHN, C. Have there been discernible shifts in American values during the past generation? In E.E. Morison (Ed.), The American style. New York: Harper and Row, 1958, 145-217. 
LANGNER, T.S. A twenty-two item screening score of psychiatric symptons indicating impairment. Journal of Health and Human Behavior, 1962, 3, 269-276.

MERTON, R.K., \& ROSSI, A.S. Contributions to the theory of reference group behavior. In R.K. Merton, Social theory and social structure. Glencoe, The Free Press, 1956, 225-280.

METTLIN, C.J. Assessing the effects of interpersonal influence in the attitude formation process. Unpublished doctoral dissertation, Department of Sociology, University of Illinois, 1970.

METTLIN, C.J. Smoking as behavior:Applying a social psychological theory. Journal of Health and Social Behavior, 1973, 14, 144-152.

METTLIN, C.J., \& WOELFEL, J. Interpersonal influence and symptons of stress. Journal of Health and Social Behavior, 1975, 16, 311-319.

McPHAIL, T. A study of interpersonal and mass communication influence. Unpublished doctoral dissertation, Department of SpeechCommunication, Purdue University, 1971.

OSGOOD, C.E., \& TANNENBAUM, P.H. The principle of congruity in the prediction of attitude change. Psychological Review 1955, 62, 42-55. 42-55.

PARSONS, T. The social system. New York: The Free Press, 1951.

REEVES, B. Predicting the perceived reality of television among elementary school children. Unpublished masters thesis, Department of Communication, Michigan State University, 1974.

ROLOFF, M.E. An application of linear force aggregation theory to the relationship between the amount of change advocated in a message and the amount of attitude change obtained. Unpublished masters thesis, Department of Communication, Michigan State University, 1974.

ROKEACH, M. The open and closed mind. New York: Basic Books, 1960.

SALTIEL, $J$. The effects of interpersonal influence on attitude formation and attitude change. Unpublished doctoral dissertation, Department of Sociology, University of Illinois, 1972.

TORGERSON, W.S. Theory and method of scaling . New York: Wiley, 1958.

WILLIAMS, R.M., JR. American society, 2nd Ed. New York: Alfred A. Knopf, 1960.
WOELFEL, J. A paradigm for research on significant others. Paper presented at the joint sessions of the American Sociological Association and the Society for the Study of Social Problems, San Francisco, 1967.

WOELFEL, J. A theory of force aggregation in attitude formation and attitude change. Unpublished manuscript, Department of Communication, Michigan State University, 1972.

WOELFEL, J., \& HALLER, A.O. Significant others, the self reflexive act and the attitude formation process. American Sociological Review, 1971, 36, 74-87.

WOELFEL, J., \& HERNANDEZ, D. Media and interpersonal effects on attitude formation and behavior. Unpublished manuscript, Department of Communication, Michigan State University, 1972.

WOELFEL, J., \& SALTIEL, J. Cognitive processes as motions in a multidimensional space. Unpublished manuscript, Department of Communication, Michigan State University, 1974.

WOELFEL, J., WOELFEL, J.C., GILLHAM, J.C., \& McPHAIL, T. Political radicalization as a communication process. Communication Research, 1974, 1, 243-263. 